\title{
Characterization of electrical penetration graphs of the Asian citrus psyllid, Diaphorina citri, in sweet orange seedlings
}

\author{
J. P. Bonani ${ }^{1}$, A. Fereres ${ }^{2}$, E. Garzo ${ }^{2}$, M. P. Miranda ${ }^{3}$, B. Appezzato-Da-Gloria ${ }^{4}$ \\ \& J. R. S. Lopes ${ }^{1 *}$ \\ ${ }^{1}$ Departamento de Entomologia e Acarologia, ESALQ/Universidade de São Paulo, CP. 9, Piracicaba, SP 13418-900, Brazil, \\ ${ }^{2}$ Departamento de Protección Vegetal, Instituto de Ciencias Agrarias (ICA, CSIC), C/Serrano, 115 dpdo, 28006 Madrid, \\ Spain, ${ }^{3}$ Fundecitrus, Av. Adhemar de Barros, 201, Araraquara, SP, CEP 14807-040, Brazil, and ${ }^{4}$ Departamento de Ciências \\ Biológicas, ESALQ/Universidade de São Paulo, CP. 9, Piracicaba, SP 13418-900, Brazil
}

Accepted: 28 September 2009

Key words: Huanglongbing, Citrus sinensis, insect vector, Psyllidae, feeding behavior, EPG, Hemiptera

\begin{abstract}
Detailed information on probing behavior of the Asian citrus psyllid, Diaphorina citri Kuwayama (Hemiptera: Psyllidae), is critical for understanding the transmission process of phloem-limited bacteria (Candidatus Liberibacter spp.) associated with citrus 'huanglongbing' by this vector. In this study, we investigated stylet penetration activities of D. citri on seedlings of Citrus sinensis (L.) Osbeck cv. Pêra (Rutaceae) by using the electrical penetration graph (EPG-DC system) technique. EPG waveforms were described based on amplitude, frequency, voltage level, and electrical origin of the observed traces during stylet penetration into plant tissues. The main waveforms were correlated with histological observations of salivary sheath termini in plant tissues, to determine the putative location of stylet tips. The behavioral activities were also inferred based on waveform similarities in relation to other Sternorrhyncha, particularly aphids and whiteflies. In addition, we correlated the occurrence of specific waveforms with the acquisition of the phloem-limited bacterium $\mathrm{Ca}$. Liberibacter asiaticus by $D$. citri. The occurrence of a G-like xylem sap ingestion waveform in starved and unstarved psyllids was also compared. By analyzing 8-h EPGs of adult females, five waveforms were described: (C) salivary sheath secretion and other stylet pathway activities; (D) first contact with phloem (distinct from other waveforms reported for Sternorrhyncha); (E1) putative salivation in phloem sieve tubes; (E2) phloem sap ingestion; and $(\mathrm{G})$ probably xylem sap ingestion. Diaphorina citri initiates a probe with stylet pathway through epidermis and parenchyma (C). Interestingly, no potential drops were observed during the stylet pathway phase, as are usually recorded in aphids and other Sternorrhyncha. Once in C, D. citri shows a higher propensity to return to non-probing than to start a phloem or xylem phase. Several probes are usually observed before the phloem phase; waveform D is observed upon phloem contact, always immediately followed by E1. After E1, D. citri either returns to pathway activity (C) or starts phloem sap ingestion, which was the longest activity observed.
\end{abstract}

\section{Introduction}

To understand the transmission process of plant pathogens by insect vectors, it is important to know the mechanisms involved in pathogen acquisition and inoculation

*Correspondence: J.R.S. Lopes, Departamento de Entomologia e Acarologia, ESALQ/Universidade de São Paulo, CP. 9, Piracicaba, SP 13418-900, Brazil.E-mail: jlopes@esalq.usp.br from/to host plants, as well as molecular and physiological interactions between the pathogen and its vector. Circulation, multiplication, or retention mechanisms of pathogens within arthropod vectors have been studied in reasonable detail for various phytopathogenic viruses and bacteria (Nault, 1997; Gray \& Banerjee, 1999; Chatterjee et al., 2008; Hogenhout et al., 2008). In contrast, the processes of acquisition and inoculation by insect vectors in plants are not well known for many pathogens, except for 
some plant viruses transmitted by aphids (Prado \& Tjallingii, 1994; Fereres \& Collar, 2001).

Detailed information on vector probing activities within plants is essential for understanding pathogen acquisition and inoculation. Unfortunately, for some important vectors of phytopathogenic bacteria, particularly psyllids and leafhoppers, little is known about their probing behavior on host plants. One example is the Asian citrus psylla, Diaphorina citri Kuwayama (Hemiptera: Psyllidae), a widespread vector of phloem-limited bacteria of the genus Candidatus Liberibacter, which are suspect causative agents of citrus 'huanglongbing' (HLB) (Bové, 2006; Sechler et al., 2009). Known in Southern Asia and Africa for decades, this serious disease is now considered to be the most important threat to citriculture in the United States of America and Brazil (Gottwald et al., 2007), where it was found recently (Coletta-Filho et al., 2004; Halbert, 2005; Teixeira et al., 2005). In this pathosystem, D. citri assumes a prominent position as a vector because it is ubiquitous and abundant in most regions where the disease is now endemic, and transmits different forms of HLB (Capoor et al., 1972; Yamamoto et al., 2006).

To study the probing behavior of sap-sucking insects, Mclean \& Kinsey (1964) developed a device to record electrical events related to stylet penetration and ingestion activities inside plant tissue, originally named the 'electronic monitoring system' (EMS). This technique consists of assembling an electric circuit that includes the insect and the plant, where stereotypical voltage fluctuations (waveforms) are associated with specific stylet activities, based on correlations with other techniques that indicate precise stylet tip position (histology) or occurrence of simultaneous ingestion, egestion, or salivation (e.g., demonstrated by honeydew excretion, membrane feeding, and virus transmission studies; Walker, 2000). Currently, this technique is termed the 'electrical penetration graph' (EPG). It can use either alternating current (AC) or direct current (DC), and allows recording of voltage fluctuations owing to insect-plant internal changes in electrical resistance (R; AC monitors, mainly), electromotive force (emf), or both (DC monitors; Tjallingii, 1978, 1988).

The probing behavior of many Sternorrhynchan species has been characterized by EPG, mainly using the DC system. DC-EPG waveforms have been well established for aphids, and are related to the phases of stylet pathway in the plant epidermis and parenchyma (waveforms A, B, C, pd, and F), xylem vessel ingestion (G), and phloem-related activities [E1 (salivation) and E2 (ingestion); Tjallingii, 1978; Prado \& Tjallingii, 1994]. For whiteflies, Janssen et al. (1989) described waveforms related to stylet pathway (A and C), xylem (G) and phloem salivation, and ingestion [E(pd)] phases. Calatayud et al. (1994) observed pathway
(A and C) and phloem (E)-associated waveforms for the cassava mealybug, Phenacoccus manihoti Matile-Ferrero. For psyllids, there is only one study of probing behavior using the AC-EPG system, in which waveforms S and I were correlated with salivation and ingestion, respectively, for the pear psylla, Psylla pyricola Foerster (Ullman \& McLean, 1988).

Despite the great importance of $D$. citri as a vector associated with HLB, little is known about its probing activities in citrus plants that result in transmission of $\mathrm{Ca}$. Liberibacter species. This knowledge is essential for establishing control methods that can interfere with the insect-feeding process and, perhaps, reduce disease spread. The goal of this article was to characterize DC-EPG waveforms related to stylet activities of $D$. citri in orange seedlings, as a basis to apply the EPG technique in studies about the transmission of plant pathogens by this vector. For this purpose, EPG waveforms produced by adults of $D$. citri on sweet orange seedlings were correlated with histological analyses of salivary sheath termini in plant tissues, starvation experiments, and the acquisition of the phloem-restricted bacterium, $\mathrm{Ca}$. Liberibacter asiaticus. In addition, the EPG signals obtained for $D$. citri were compared with waveforms already described for other sternorrhynchan species.

\section{Materials and methods}

\section{Insects and plants}

A healthy D. citri colony was maintained on potted plants of Murraya paniculata (L.) Jack (Rutaceae), which is an optimum rearing host for this insect (Tsai et al., 2002). The insects were reared inside screened cages with aluminum frame $(35 \times 35 \times 53 \mathrm{~cm})$ and acrylic door, maintained in a climate-controlled room $\left(25 \pm 2{ }^{\circ} \mathrm{C}, 70 \pm 10 \%\right.$ r.h., and L14:D10 photoperiod), under fluorescent light bulbs $(80 \mathrm{~W})$. Young adult females (5-10 days old) were used in the EPG study, after a 2-day adaptation period on healthy sweet orange seedlings, Citrus sinensis (L.) Osbeck cv. Pêra (Rutaceae). Similar seedlings (20-25 cm tall) were used for the EPG recordings. These seedlings were grown in $0.5-1$ plastic bags containing soil, manure, and sand (3:1:1), inside a vector-proof greenhouse.

\section{Electrical penetration graph recordings}

The experiment was conducted in a climate-controlled room with similar light, temperature, and photoperiod conditions described for insect rearing. EPG records were obtained using a DC-monitor, GIGA-8 model (EPG-Systems, Wageningen, the Netherlands) (Tjallingii, 1978, 1988 ), adjusted to $100 \times$ gain. The analog signal was digitalized through a DI-710 board (Dataq ${ }^{\circledR}$ Instruments, 
Akron, OH, USA) in a Pentium $4{ }^{\circledR}$ computer, where the data were acquired, stored, and analyzed, using the software Probe 3.0 for Windows (Laboratory of Entomology, Wageningen University, The Netherlands).

The psyllids were anesthetized with $\mathrm{CO}_{2}$ for $3 \mathrm{~s}$ and immediately immobilized using a vacuum chamber similar to that described by van Helden \& Tjallingii (2000), under a dissecting microscope. A $20-\mu \mathrm{m}$-diameter, $3-\mathrm{cm}$ long gold wire (Sigmund Cohn, Mount Vernon, NY, USA) - previously attached to a copper electrode measuring $3 \mathrm{~cm}$ length and $1 \mathrm{~mm}$ diameter - was placed on the insect pronotum and glued by a water-based glue (Entomology, Wageningen). The electrode was then attached to the EPG probe and the tethered insect was placed on the abaxial surface of a young citrus leaf, which is the preferred feeding site for D. citri (JP Bonani, unpub.). To complete the electrical circuit, another electrode (copper, $10 \mathrm{~cm}$ long $\times 2 \mathrm{~mm}$ wide) was the plant electrode and was inserted into the pot substrate containing the citrus seedling. The monitoring system was assembled inside a Faraday cage $(100 \times 110 \times 90 \mathrm{~cm})$.

Each psylla was monitored for $8 \mathrm{~h}$ during the photophase (09:00-17:00 hours) and the data of 20 individuals were analyzed using Probe 3.0. EPG waveforms were described based on amplitude spectrum analysis (maximum and minimum), frequency $(\mathrm{Hz})$, voltage level (extracellular or intracellular), and main electrical origin ( $\mathrm{R}$ or emf) of the observed signals during stylet penetration into plant tissues. To determine the electrical origin, voltage adjustments to positive and negative levels were performed in different periods for each observed waveform. Amplitude and frequency were estimated based on the average of 60 observations in different points for each waveform (three observations per insect).

The typical sequence of events that are likely to occur during stylet penetration was studied, by estimating the conditional probabilities of a certain waveform type being followed by another, based on data of $160 \mathrm{~h}$ of EPG recordings ( 8 h per individual; Wayadande \& Nault, 1996; Almeida \& Backus, 2004; Miranda et al., 2009). We also calculated selected non-sequential parameters (Backus et al., 2007) such as the proportion of individuals that produced each waveform type, mean number of times the waveform was produced per individual, total time spent per individual in the waveform, and mean duration of a given waveform, as well as selected sequential parameters using an Excel computer workbook for automatic EPG parameter calculation (Sarria et al., 2009).

\section{Plant tissue histology}

We used plant tissue histology to determine the position of salivary sheath termini during the different types of waveforms observed in the EPG recordings. For this analysis, another set of $D$. citri adult females was monitored on similar citrus seedlings and under the same conditions used for EPG data acquisition. Psyllid probing was artificially terminated by removing the insect from the plant when the distinct EPG waveforms of interest were observed. An area of ca. $0.5 \mathrm{~cm}^{2}$ of leaf tissue around the insect-probing site was removed from the plant, and immersed in acid fucsin (1\%) during 3 min for staining the salivary flange produced by the insect during the beginning of the probe and determining the stylet insertion point (Miranda et al., 2009). Afterwards, the leaf tissue was washed in distilled water and dried on filter paper, and then fixed in Karnovsky solution (Karnovsky, 1965), dehydrated in ethyl alcohol series, and embedded in plastic resin (Leica Historesin, Heidelberg, Germany). Serial transverse sections $(12-\mu \mathrm{m}$ thick) were cut on a rotary microtome and stained with toluidine blue O (Sakai, 1973). Permanent slides were mounted in synthetic resin. The images were digitally captured through a Leica DM LB microscope using a video camera coupled to a computer, using software IM50 (Leica, Wetzlar, Germany) for image analysis.

\section{Association of waveform $\mathbf{G}$ with xylem ingestion}

To correlate waveform $G$ with xylem sap ingestion, we compared the occurrence and duration of this waveform in 5-h EPG recordings of 10 young psyllid adult females (5-10 days old) that were either previously starved for $24 \mathrm{~h}$ inside an empty plastic vial, or kept on sweet orange seedlings (non-starved). This experiment was based on the hypothesis that starved psyllids are more likely to ingest xylem sap to maintain their water balance, as earlier observed for aphids (Spiller et al., 1990). Thus, if G is associated with xylem ingestion, starved psyllids should perform this waveform more frequently than non-starved ones. The EPG recordings were conducted under the same conditions as previously described.

\section{Correlation of waveforms with phloem ingestion}

The phloem-limited bacterium Ca. L. asiaticus was used as a marker to assess phloem ingestion by $D$. citri during waveforms $\mathrm{C}, \mathrm{E} 1$, and E2. Healthy and young (3-5 days old) adult females were tethered to a gold wire and connected to the EPG system as described before, and then individually placed on young leaves of potted citrus plants infected with the bacterium (source plants). We monitored the stylet penetration activities in the infected-source plants by using a computer display connected to the EPG system, and artificially terminated psyllid probing after the onset of distinct waveform types and specific durations: (1) waveform C for $20 \mathrm{~min}$, (2) waveforms C + D + 30 s 
in E1, and (3) C + D + E1 + 1 h in E2. Fifty insects were subjected to each treatment on the source plant. After probing was artificially interrupted, each insect was individually confined on healthy sweet orange seedlings inside leaf cages for a latent period of 4 weeks in a growth chamber $\left(25 \pm 1{ }^{\circ} \mathrm{C}, 70 \pm 10 \%\right.$ r.h., L14:D10 photoperiod), and then evaluated for bacterial infectivity by real-time polymerase chain reaction (RT-PCR), to determine if bacterial acquisition occurred under each specific stylet activity treatment. The presence of the bacteria in the vector is an unequivocal indication that phloem sap ingestion did really happen. As a negative control for vector infectivity, a group of 50 psyllids from the same rearing batch, but not exposed to the source plants, were simultaneously confined on healthy citrus seedlings, and tested by RT-PCR 28 days later.

Total DNA of individual psyllids was extracted based on the protocol of Deng et al. (2006), with some modifications. After cell digestion with proteinase $\mathrm{K}$ and brief centrifugation to remove any large debris, the supernatant was submitted to an additional purification step using Wiz$\operatorname{ard}^{\circledR}$ Genomic DNA Purification kit (Promega, Madison, WI, USA); purified DNA was eluted in $50 \mu \mathrm{l}$ of elution buffer (10 mm Tris, $1 \mathrm{~mm}$ EDTA, $20 \mu \mathrm{g} \mu^{-1}$ RNAse). Total DNA from $0.25 \mathrm{~g}$ (fresh weight) of citrus leaf midribs and petioles infected with $\mathrm{Ca}$. L. asiaticus was extracted according to the cetiltrimethylammonium bromide method of Murray \& Thompson (1980), and used as a positive control in the RT-PCR; DNA was eluted in $100 \mu \mathrm{l}$ of the elution buffer.

The RT-PCR assay was carried out with primers (AS84F and AS180R) and probe (As111T) designed based on the $16 \mathrm{~S}$ rDNA sequence of $\mathrm{Ca}$. L. asiaticus (GenBank AY919311; Carlos et al., 2006; Coletta-Filho et al., 2009). The assay required $0.8 \mu \mathrm{M}$ of each of the forward and reverse primers and $0.2 \mu \mathrm{M}$ of the probe for $\mathrm{Ca}$. L. asiaticus, 1× TaqMan fast universal Master Mix (Applied Biosystems, Foster City, CA, USA), $4 \mu \mathrm{l}$ of standardized DNA template $\left(10 \mathrm{ng} \mu^{-1}\right), 1 \mu$ of Eukaryotic $18 \mathrm{~S}$ rRNA kit (Applied Biosystems) as an internal control for normalization of the amount of total DNA in each reaction, and autoclaved Milli-Q water to a final volume of $20 \mu \mathrm{l}$. Amplification conditions were the same as described by Coletta-Filho et al. (2009) The amplification, data acquisition, and data analysis were done with the ABI PRISM 7500 Fast Sequence Detection System (Applied Biosystems) using the sequence detection software (version 1.4). Each run comprised of three replicates for the tested DNA, the negative and positive controls, and the non-template control (NTC). Samples were considered positive for Ca. L. asiaticus when the mean cycle threshold (Ct) was lower than 36.

\section{Results}

Characterization of Diaphorina citri's electrical penetration graph waveforms

Diaphorina citri adult females produced five distinct types of EPG waveforms, which were described based on their morphology (amplitude, frequency) and electrical (voltage level, electrical origin) characteristics, association with stylet sheath termini position in the plant tissue, and putative behavioral activity (based on aphid activities). Because of the similarities to DC-EPG waveforms described for aphids (Tjallingii, 1978; Spiller et al., 1990; Prado \& Tjallingii, 1994), we adopted the same terminology to name D. citri waveforms as: $\mathrm{C}$, probably representing secretion of salivary sheath and intercellular stylet pathway in epidermis and parenchyma; E1, putative phloem salivation; E2, phloem sap ingestion; and G, probably xylem sap ingestion. In addition, we found a previously unreported waveform type associated with phloem, which was named D.

The main characteristics of the observed waveforms and their correlations with stylet activities in the plant tissues are summarized in Table 1 and Figures 1-3. Waveform C is complex, showing extracellular voltage level and significant oscillations in frequency $(11.5-19 \mathrm{~Hz})$, with average amplitude of $45 \%$ (Table 1 and Figure 1B). It is the first waveform event observed in all probes, with mean duration of 10 min per event (Table 2). The $\mathrm{G}$ waveform shows high amplitude (50-90\%), extracellular voltage level, and frequency ranges of $5-7 \mathrm{~Hz}$ for waves and $6-8 \mathrm{~Hz}$ for peaks (Table 1 and Figure $1 \mathrm{C}$ ). This waveform was observed only in $25 \%$ of the individuals, with mean duration of 23.7 min per event (Table 2). Waveform D is characterized by a frequency of $1-3.5 \mathrm{~Hz}$ and extracellular voltage level (Table 1 and Figure 2); it is a short waveform (46 s per event, on average), and was always observed between waveforms $\mathrm{C}$ and $\mathrm{E} 1$ (Table 2).

E1 waveform always started with a potential drop after waveform D (Figure 2), showing a frequency range of $5.0-7.5 \mathrm{~Hz}$, and negative voltage level (Figure 3A); the latter is indicative of intracellular activity (Table 1). An E1 waveform event can be followed by either E2 or $\mathrm{C}$ (stylet pathway); in the latter case, it was named terminal E1. The mean duration of a terminal E1 event (1.24 $\mathrm{min})$ is numerically shorter than an E1 followed by E2 (1.65 min; Table 2), although this was not tested statistically. Waveform E2 was always preceded by E1, showing intracellular voltage level and variable amplitude (10-40\%), with frequency range of 3-8 and 3-9 $\mathrm{Hz}$ for waves and peaks, respectively (Table 1 and Figure 3B). The mean duration of an E2 event was long (150.2 min per event) compared with other waveforms observed for D. citri (Table 2). 
Table 1 Summary of the main characteristics and correlations of Diaphorina citri DC electrical penetration graph (EPG) waveforms on Citrus sinensis

\begin{tabular}{|c|c|c|c|c|c|c|}
\hline \multirow[b]{2}{*}{$\begin{array}{l}\text { EPG } \\
\text { waveform }\end{array}$} & \multicolumn{4}{|c|}{ Waveform characteristics } & \multicolumn{2}{|l|}{ Correlations } \\
\hline & $\%$ amplitude $^{1}$ & $\begin{array}{l}\text { Frequency } \\
(\mathrm{Hz})\end{array}$ & Voltage level & Electrical origin & $\begin{array}{l}\text { Stylet tips in } \\
\text { plant tissue }\end{array}$ & $\begin{array}{l}\text { Putative } \\
\text { activity }\end{array}$ \\
\hline $\mathrm{C}$ & 45 & $11.5-19.0$ & Extracellular & Resistance & Parenchyma & $\begin{array}{l}\text { Salivary sheath } \\
\text { secretion and } \\
\text { other stylet pathway } \\
\text { activities }\end{array}$ \\
\hline $\mathrm{D}$ & - & $1.0-3.5$ & Extracellular & Electromotive force & Phloem & Unknown \\
\hline E1 & - & $5.0-7.5$ & Intracellular & Electromotive force & Phloem & Salivation \\
\hline E2 waves & - & $3.0-8.0$ & Intracellular & Electromotive force & Phloem & Ingestion \\
\hline E2 peaks & $10-40$ & $3.0-9.0$ & Intracellular & Resistance & & \\
\hline G waves & - & $5.0-7.0$ & Extracellular & Electromotive force & Xylem & Ingestion \\
\hline G peaks & $50-90$ & $6.0-8.0$ & Extracellular & Resistance & & \\
\hline
\end{tabular}

${ }^{1}$ Medium amplitude; $5 \mathrm{~V}=100 \%$ amplitude; applicable only for waveforms with a main R origin.

\section{Correlations between electrical penetration graph waveforms and salivary sheath termini in the plant}

Histological analyses are important to determine salivary sheath termini position in the plant tissue and possible behavioral activities associated with the EPG waveforms. After initial penetration into the abaxial leaf surface, stylets appear to move intercellularly through epidermis and parenchyma, because no visible damage was observed in plant cells surrounding the salivary sheath along the pathway to the phloem (Figure 4). Penetration through stomata was not observed. In addition, no potential drops, which are indicative of intracellular penetration, were present in any of the 20 8-h EPG recordings.

Salivary sheath termini were examined for each of the waveform types described before, except $G$, which was not frequently observed for D. citri. For waveform C, the analyses of all salivary sheaths $(n=6)$ indicated stylet pathway through parenchyma tissue, i.e., sheath termini were always in this tissue (Figure 5A). For waveforms D and E1, all sections $(n=5)$ showed salivary sheath termini in the phloem (Figures 4A,D and 5F). During waveform E2, all salivary sheaths $(n=6)$ also ended in the phloem tissue (Figure 5B-E). One salivary sheath examined for waveform E2 was branched (Figure 5E). Most likely this happened because the insect did not find an adequate phloem sieve element for feeding in the first attempt, and then searched for another sieve element, producing the branched sheath.

Occurrence and duration of electrical penetration graph waveforms during stylet penetration of Diaphorina citri

Conditional probabilities for sequences of events during stylet penetration of $D$. citri on citrus leaves, as well as EPG parameters related to occurrence and total duration of waveforms, were determined based on recorded data of 20 adult females ( $8 \mathrm{~h}$ per individual). All probes started with waveform $\mathrm{C}$, representing the pathway phase through epidermis and parenchyma. Once in C, D. citri showed a much higher propensity to return to non-probing (Np; $86.2 \%)$ than to start a phloem $(12.5 \%)$ or xylem phase (1.3\%; Figure 6).

Diaphorina citri usually pulled the stylets out of the plant and soon restarted penetration several times before reaching the phloem or xylem. Tethered psyllids started a first probe in a few minutes after being placed on the plant (Table 3); first and second probes were usually short, lasting $0.97 \pm 0.32$ and $0.91 \pm 0.21 \mathrm{~min}$, respectively. Most of the probes occurred before the first E1 (phloem phase), particularly in the first hour; likewise, short probes ( $<3 \mathrm{~min}$ ) were more frequent before E1/E2 (Table 3). Despite the relatively long time spent in stylet pathway (around $2.5 \mathrm{~h}$ per insect, on average) or non-probing (almost $2 \mathrm{~h}$ per insect), all $20 \mathrm{D}$. citri females reached the phloem phase, which represented a predominant activity (around $3.5 \mathrm{~h}$ per insect; Table 2). In contrast, the xylem phase (waveform G) was observed in only 4 out of 20 individuals; these individuals spent $<1 \mathrm{~h}$, on average, performing waveform G during the $8 \mathrm{~h}$. A return to pathway phase (C waveform) was always observed after $\mathrm{G}$ (Figure 6).

$\mathrm{D}$ is the first waveform observed upon phloem contact, always followed by E1 (Figure 6). Once in E1, D. citri can either return to waveform $\mathrm{C}$ ( $55 \%$ probability) or initiate E2 (45\%). A terminal E1 (not followed by E2) was observed in 9 out of 20 individuals tested (Table 2). A terminal E1 may represent stylet penetration and salivation into a sieve element eventually found to be unsuitable for 

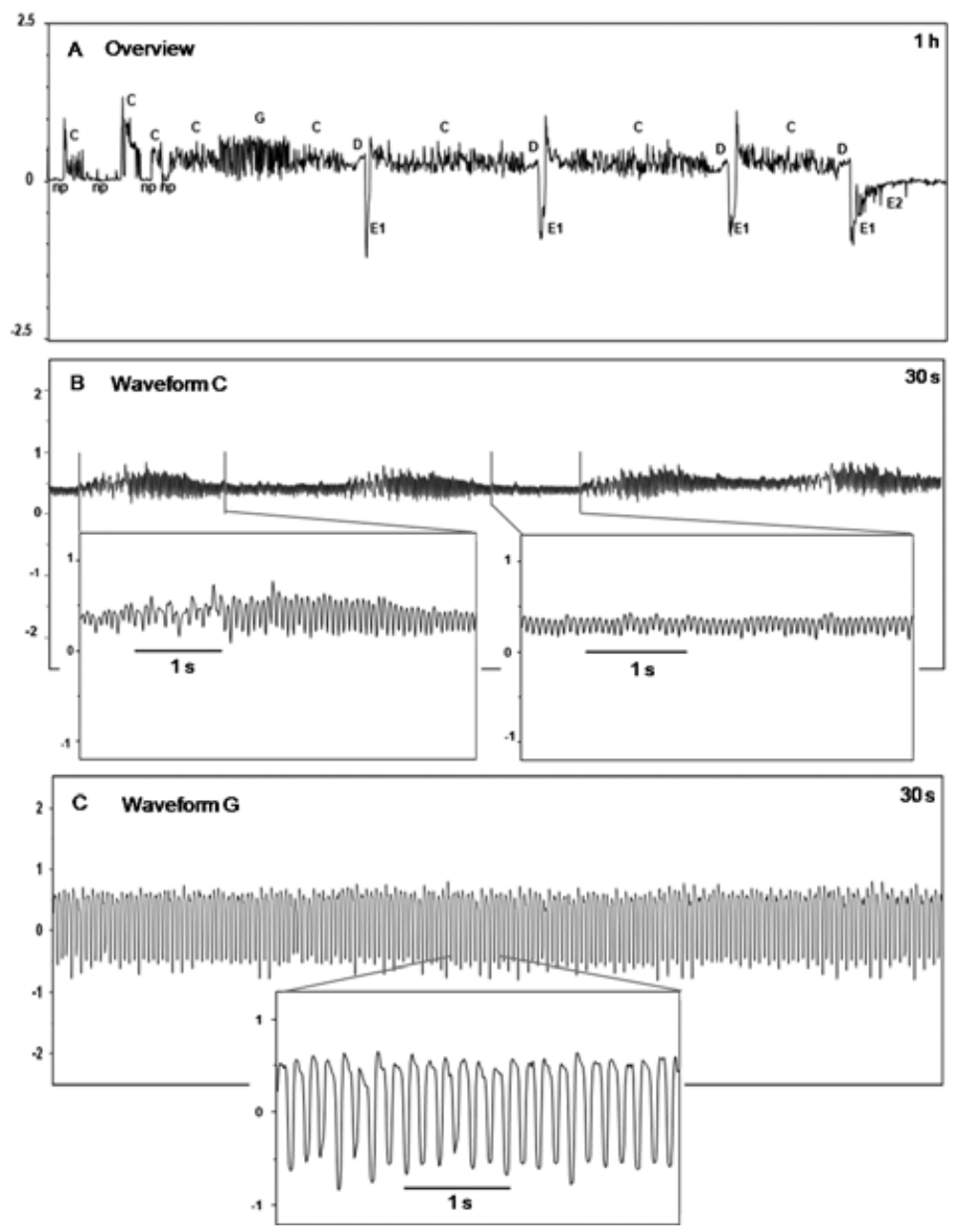

Figure 1 Electrical penetration graph (EPG) waveforms produced by Diaphorina citri on young leaves of Citrus sinensis. (A) General scheme of characteristic EPG waveforms. (B, C) Representative traces of waveforms $\mathrm{C}$ and $\mathrm{G}$, respectively, with higherresolution views in the inset boxes. ingestion, resulting in stylet withdrawal and subsequent search for another sieve element. The occurrence of this behavior in $D$. citri is supported by histological observation of a branched salivary sheath terminus in the phloem tissue after E2 was initiated (Figure 5E). Waveform E2 was performed less than twice per individual, on average. Nevertheless, E2 is the waveform with the longest total duration per individual insect (Table 2), which is an evidence of phloem ingestion habit for this psyllid species. After terminating E2, psyllids always returned to waveform C (Figure 6).

From the onset of the first probe, $D$. citri required ca. $2.5 \mathrm{~h}$, on average, to start phloem phase (first E1); in 20 individuals recorded, the fastest one started the first E1 in $50.1 \mathrm{~min}$ (Table 3). Because of the limited number of $D$. $c i$ tri individuals recorded in this study $(\mathrm{n}=20)$, it is not yet possible to have an accurate estimate of the minimum time required for this vector to reach the phloem sieve elements in citrus, which is particularly important for acquisition and inoculation of phloem-limited bacteria such as $C a$. Liberibacter spp. If hundreds of individuals are evaluated, we expect that some will start the phloem phase in time intervals probably shorter than the minimum period reported here (Table 3 ). This expectation is supported by the fact that duration of $\mathrm{C}$ before the first E1 (i.e., considering only the probes that resulted in phloem contact) was less than $30 \mathrm{~min}$, on average, and as short as ca. 9 min for one of the individuals.

As mentioned before, not all E1 were followed by E2. Therefore, the mean time elapsed between start of the first probe and the first E1/E2 is longer than that to the first E1 (Table 3). About $90 \%$ of all E2>40 $\mathrm{min}(\mathrm{n}=28)$ were also longer than $1 \mathrm{~h}$, which might be indicative of sustained phloem ingestion; the mean time to start an E2>40 min from onset of the first probe was $198.9 \pm 20.4 \mathrm{~min}$. However, further studies using more insects are needed to establish an accurate time threshold as an indicative of sustained phloem ingestion. 
Table 2 Occurrence and mean ( \pm SE) duration of DC-electrical penetration graph (EPG) waveforms of Diaphorina citri during an 8-h access period to young leaves of Citrus sinensis. Sample size is 20, unless stated otherwise; value ranges are given in parentheses. Selected non-sequential statistical parameters as in Backus et al. (2007): PPW, proportion of individuals that produced the waveform type; NWEI, number of waveform events per insect; WDI, waveform duration ( $\mathrm{min}$ ) per insect; WDE, waveform duration (min) per event

\begin{tabular}{|c|c|c|c|c|}
\hline EPG waveform & PPW & NWEI & WDI & WDE \\
\hline $\mathrm{Np}$ & $20 / 20^{1}$ & $30.7 \pm 4.0(3-71)$ & $115.9 \pm 13.4(0.38-226.9)$ & $4.2 \pm 0.5(0.13-10.4)$ \\
\hline $\mathrm{C}$ & $20 / 20$ & $34.3 \pm 4.0(3-73)$ & $157.1 \pm 18.0(60.0-343.6)$ & $10.0 \pm 4.2(1.8-87.5)$ \\
\hline $\mathrm{D}$ & $20 / 20$ & $3.7 \pm 0.9(1-16)$ & $2.74 \pm 0.65(0.38-12.3)$ & $0.77 \pm 0.05(22.8-78.0)$ \\
\hline Terminal $E 1^{2}$ & $9 / 20$ & $1.9 \pm 0.7(0-12)$ & $3.3 \pm 1.3(\mathrm{n}=9 ; 0.51-12.3)$ & $1.24 \pm 0.64(\mathrm{n}=9 ; 0.31-6.36)$ \\
\hline $\mathrm{E} 1^{3}$ & $20 / 20$ & $1.8 \pm 0.2(1-4)$ & $3.1 \pm 0.7(0.54-13.0)$ & $1.65 \pm 0.22(0.31-3.6)$ \\
\hline E2 & $20 / 20$ & $1.8 \pm 0.2(1-4)$ & $206.1 \pm 25.1(17.8-389.0)$ & $150.2 \pm 24.3(8.9-389.0)$ \\
\hline G & $4 / 20$ & $0.45 \pm 0.2(0-3)$ & $46.0 \pm 4.8(\mathrm{n}=4 ; 36.0-55.9)$ & $23.7 \pm 5.1(\mathrm{n}=4 ; 13.2-36.0)$ \\
\hline
\end{tabular}

${ }^{1}$ Number of individuals that produced the waveform type over the total number of individuals recorded.

${ }^{2}$ E1 waveform not followed by E2.

${ }^{3} \mathrm{E} 1$ waveform followed by E2.

Figure 2 Waveform D observed in electrical penetration graphs of Diaphorina citri on young leaves of Citrus sinensis. Representative traces are shown with higher resolution in the inset boxes.
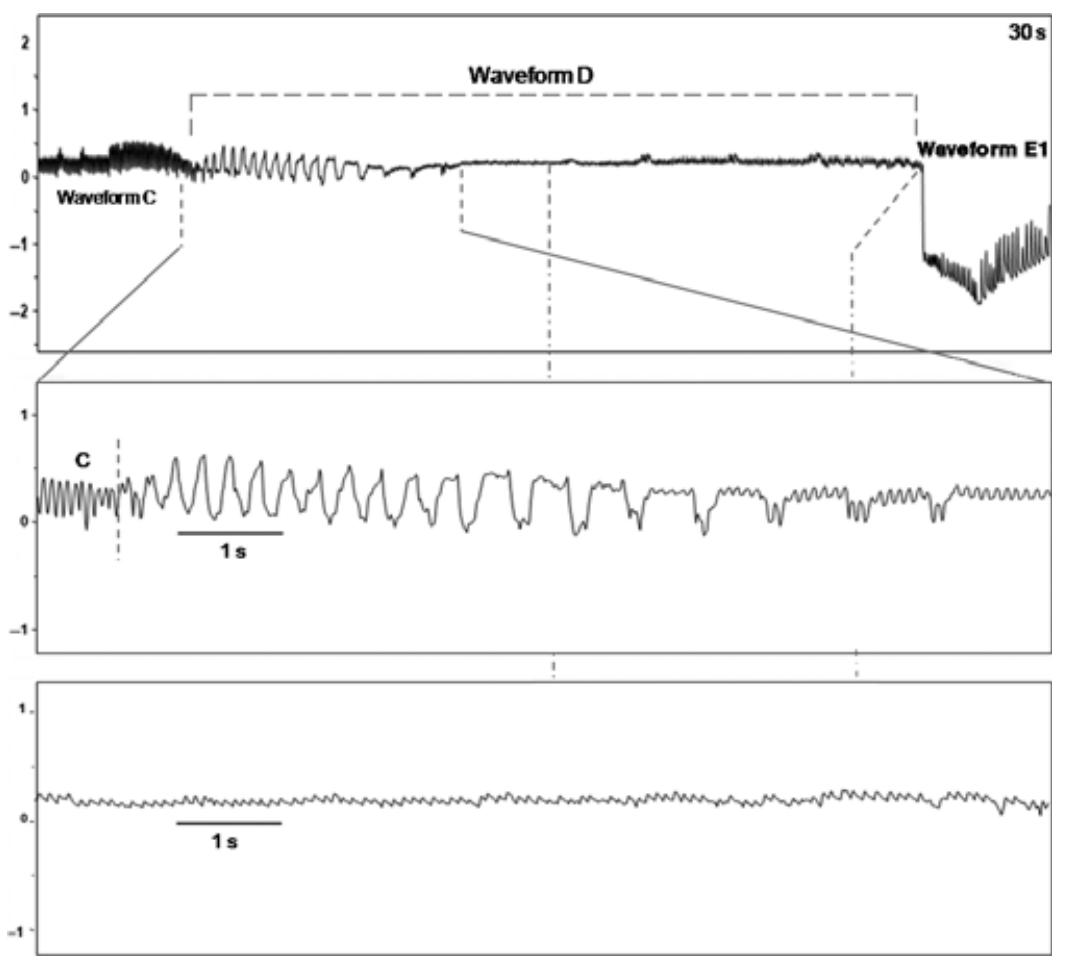

\section{Effects of starvation of Diaphorina citri on the occurrence of wave- form G}

When submitted to a 24-h starvation period, 7 out of 10 psyllids performed waveform $\mathrm{G}$, with an average of 0.7 events per insect in 5-h EPG recordings; mean G waveform durations per event and per starved insect were the same $(47.2 \pm 10.8 \mathrm{~min} ; \mathrm{n}=7)$, ranging from 29.0 to $109.5 \mathrm{~min}$. In contrast, none of the 10 non-starved pysllids produced waveform $\mathrm{G}$ during the same recording period in this experiment.

\section{Association of bacterial acquisition with electrical penetration graph waveforms}

None of the 50 test psyllids were positive for $\mathrm{Ca}$. L. asiaticus by RT-PCR when probing on infected plants was artificially terminated after $20 \mathrm{~min}$ in waveform C, or after waveforms C (complete) + D (complete) + E1 (30 s), indicating that this phloem-limited bacterium was not acquired, neither during stylet pathway through the epidermis and parenchyma (waveform C), nor during waveforms D and E1. In contrast, 3 out of 50 (6\%) psyllids 

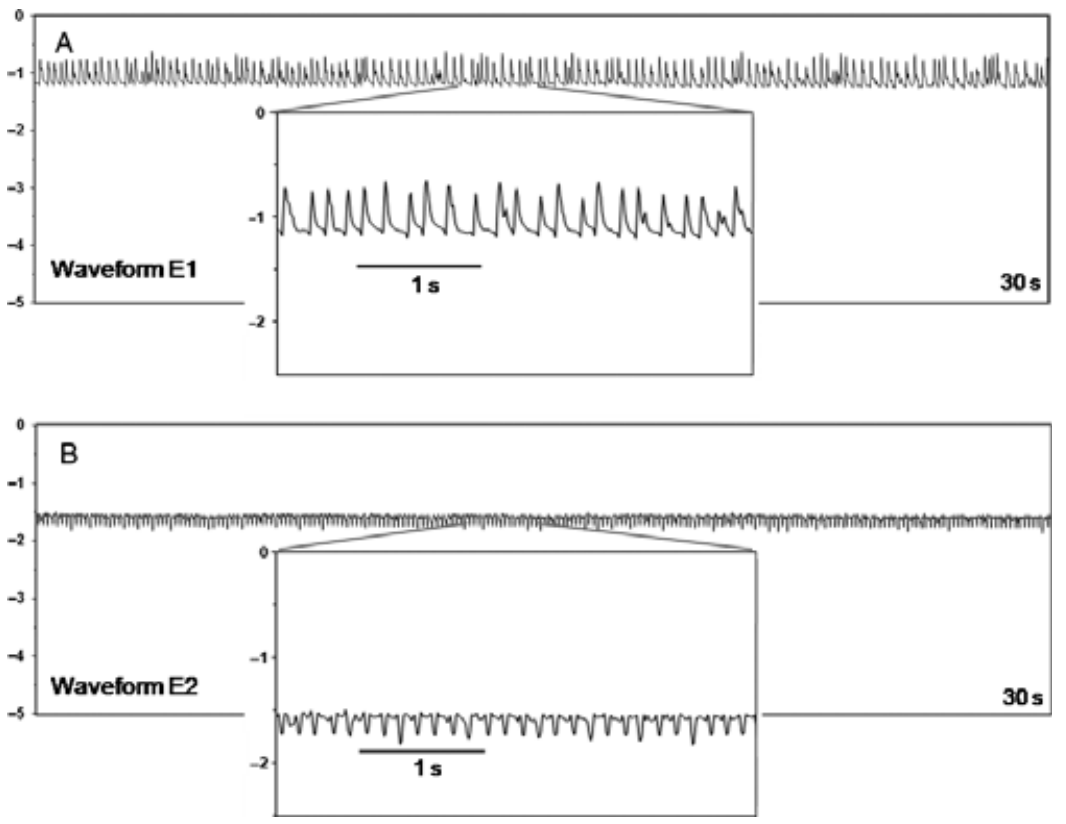

Figure 3 Waveforms E1 and E2 observed in electrical penetration graphs of Diaphorina citri on young leaves of Citrus sinensis. (A, B) Representative traces of E1 and E2, respectively, with higher-resolution views in the inset boxes. tested positive by RT-PCR when allowed to perform an E2 waveform for a period of $1 \mathrm{~h}$ (which was preceded by complete C, D, and E1 waveforms), showing that bacterial acquisition occurred during E2. Candidatus L. asiaticus was not detected in any of the 50 psyllids unexposed to infected plants (negative control), indicating that laboratory-reared insects used in the experiment were not infec-

Table 3 Mean ( \pm SE) electrical penetration graph (EPG) parameter values (ranges in parentheses) characterizing probing behavior of Diaphorina citri during an 8-h access period to young leaves of Citrus sinensis, based on data of 20 individuals. Selected sequential statistical parameters as in Sarria et al. (2009)

\begin{tabular}{lr}
\hline No. probes & $30.5 \pm 4.0(1-71)$ \\
During $8 \mathrm{~h}$ & $13.5 \pm 1.7(1-26)$ \\
In the first hour & $3.3 \pm 0.9(0-15)$ \\
In the second hour & $18.5 \pm 2.7(1-40)$ \\
Before first E1 & $10.1 \pm 3.4(0-58)$ \\
After first E1/E2 ${ }^{2}$ & $23.8 \pm 3.5(1-47)$ \\
$<3$ min before E1/E2 & $7.8 \pm 3.1(0-50)$ \\
$<3$ min after E1/E2 & $3.1 \pm 1.2(0.24-25.0)$ \\
Time (min) elapsed to & \\
First probe from & $154.9 \pm 20.9(50.1-307.2)$ \\
$\quad$ beginning of experiment & \\
First E1 from & $177.8 \pm 22.7(51.9-352.3)$ \\
$\quad$ start of first probe & \\
First E1/E2 from & \\
$\quad$ start of first probe & \\
First E1 from & \\
$\quad$ start of the probe & \\
\hline
\end{tabular}

${ }^{1}$ E1/E2, waveform E1 followed by E2. tive before being exposed to the Liberibacter-infected source plants.

\section{Discussion}

EPG studies using both AC and DC systems have built a detailed knowledge on the feeding behavior of more than 50 species of pierce-sucking insects, particularly aphids, whiteflies, and leafhoppers (Backus, 1994). These findings have contributed with critical information to a better understanding of their interactions with host plants, e.g., plant resistance mechanisms (Garzo et al., 2002; Alvarez et al., 2006; Ameline et al., 2007) and transmission of plant pathogens (Prado \& Tjallingii, 1994; Martin et al., 1997; Collar \& Fereres, 1998; Moreno et al., 2005; Stafford et al., 2009).

Compared with that of other sternorrhynchans (e.g., aphids, whiteflies, and mealybugs), probing behavior of psyllids has received little attention. In the present study, we described five DC-EPG waveforms associated with the probing activities of the Asian citrus psylla, D. citri, an important vector of bacterial pathogens that probably cause citrus HLB in Asia, Africa, and Americas (Gottwald et al., 2007; Sechler et al., 2009). Previously, a study on probing activities of nymphs and adults of the pear psylla, P. pyricola, using the AC system (Ulman \& McLean, 1988) was the only EPG information available on psyllid feeding behavior. They identified a waveform S, correlated with salivation, and another named I, representing ingestion. Because their work was performed with the AC system and with different psyllid and host plant species, one can only correlate the broadest (phase) level of information 
Figure 4 Cross-sections of a salivary sheath of Diaphorina citri left in Citrus sinensis leaf midrib when probing was artificially terminated during waveform E1. (A) Overview of complete salivary sheath starting in the lower epidermis and ending in the phloem (arrow). The area within the box, representing stylet pathway in the epidermis and parenchyma, is shown in greater detail in (B). (C) Magnified view of the salivary sheath surrounding intact epidermal and parenchyma cells, suggesting intercellular stylet penetration. (D) Detail of the salivary sheath terminus in the phloem tissue (arrow). The area within the box, representing stylet pathway, is shown with higher magnification in (E) and (F), which were captured with distinct focus positions to show the integrity of parenchyma cells along the pathway. Ep, leaf epidermis; Fi, undifferentiated pericyclic fibers; $\mathrm{Pa}$, parenchyma; Ph, phloem; Pr, procambium; Xy, xylem. A pink line was drawn around the salivary sheaths to make clear the sheath borders.
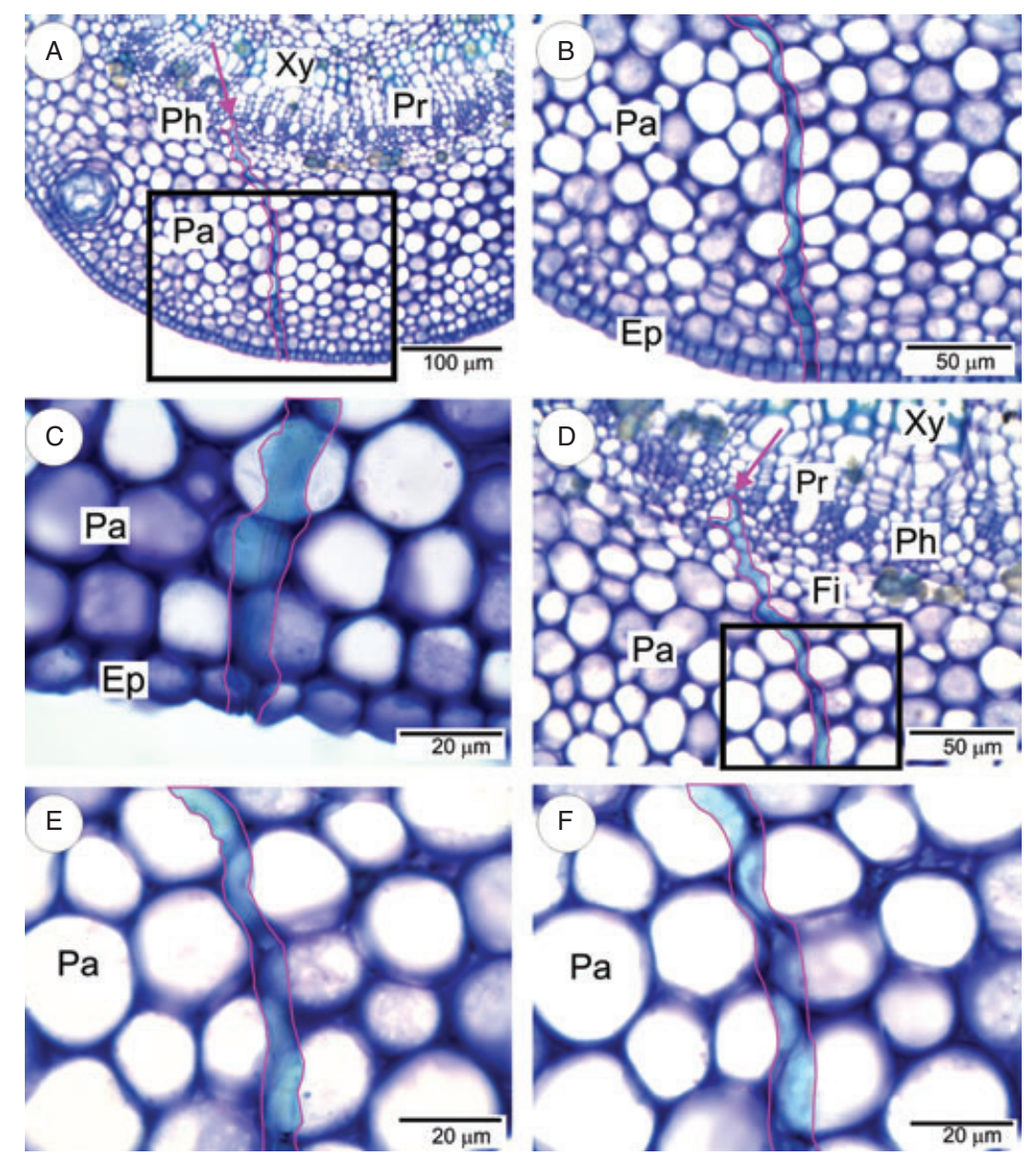

between their study and ours. Both studies indicate that the predominant psyllid waveform types occur in pathway and ingestion phases. We found evidence that ingestion by D. citri may occur both in phloem and xylem tissues. Nevertheless, the much larger occurrence and longer duration spent in the phloem (206.1 min; i.e., $42.9 \%$ of the average probing duration per insect) indicates that $D$. citri is probably primarily a phloem feeder, as previously proposed for Psyllidae in general (Hodkinson, 1974). Ulman \& McLean (1988) observed that $P$. pyricola ingests from different plant tissues, not only from the phloem. Interestingly, they reported that both nymphs and adults show a constant movement of antennae during stylet penetration, which persisted after continuous ingestion started.

\section{Electrical penetration graph waveforms and correlation with probing} activities

DC-EPG waveforms and behavioral activities associated with $D$. citri were proposed based on correlation with salivary sheath termini position in the plant tissues, acquisition of a phloem-limited bacterium (used as a marker of phloem ingestion), and the effects of starvation on particu- lar xylem-related activities (increased propensity to ingest from xylem vessels), as well as on similarities to DC-EPG waveforms previously described for other sternorrhynchans, especially aphids (Tjallingii, 1978; Spiller et al., 1990; Prado \& Tjallingii, 1994).

\section{Waveform C}

For D. citri, this waveform was correlated with sheath saliva secretion and stylet pathway activities through parenchyma. Based on DC-EPG recordings of aphids, Tjallingii $(1978,1985)$ reported that $C$ is a complex waveform, and might resemble other waveform types with respect to amplitude level (30\%) and frequency of peaks, which are highly variable. During C, aphid stylets might be in different plant tissues and the activity is mainly intercellular, but potential drop (pd) waveforms associated with cell puncturing are frequently observed (Reese et al., 1994). Aphids usually perform several superficial test probes during which epidermal, mesophyll, and parenchyma cells are punctured (pds). This behavior is often associated with host plant selection (Wensler \& Filshie, 1969; Powell et al., 2006) and is very 

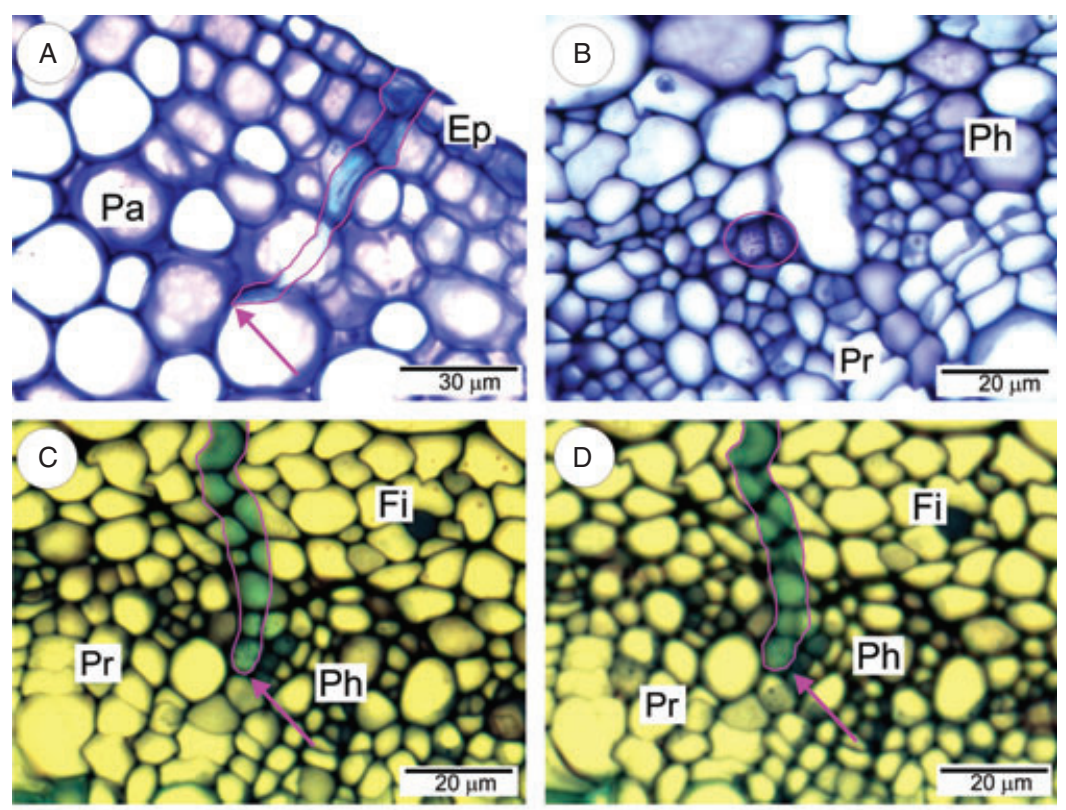

Figure 5 Cross-sections of Citrus sinensis leaf midribs containing Diaphorina citri salivary sheaths. (A) Salivary sheath ending in parenchyma tissue (arrow) during waveform C. (B) Detail of typical citrus phloem sieve elements in circled area. (C, D) Salivary sheath terminating near a similar sieve element (arrows) during waveform E2; the two pictures were captured with distinct focus positions and using a yellow filter to
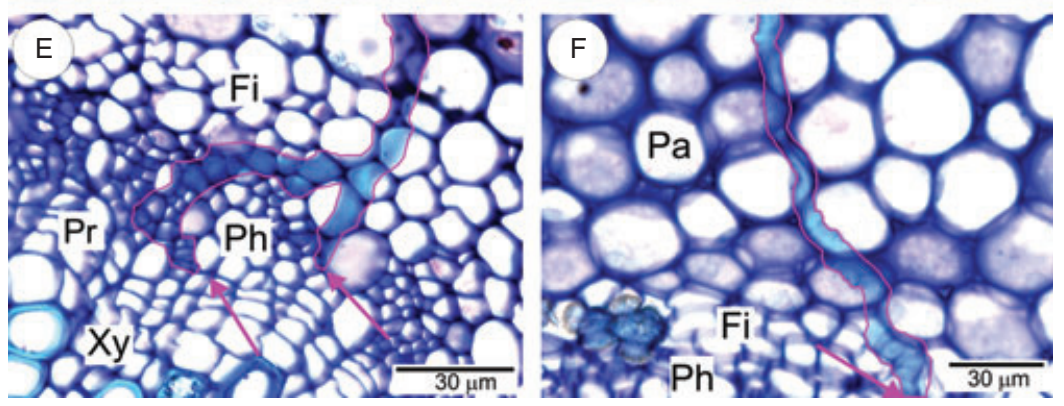

show the lack of cell damage along the stylet pathway. (E) Branched salivary sheath termini in the phloem tissue (arrows) during E2. (F) Salivary sheath reaching phloem tissue (arrow) during waveform $\mathrm{D}$, after crossing the undifferentiated pericyclic fibers (Fi). Ep, epidermis; Pa, parenchyma; Ph, phloem; Pr, procambium; Xy, xylem. A pink line was drawn around the salivary sheaths to make clear the sheath borders.

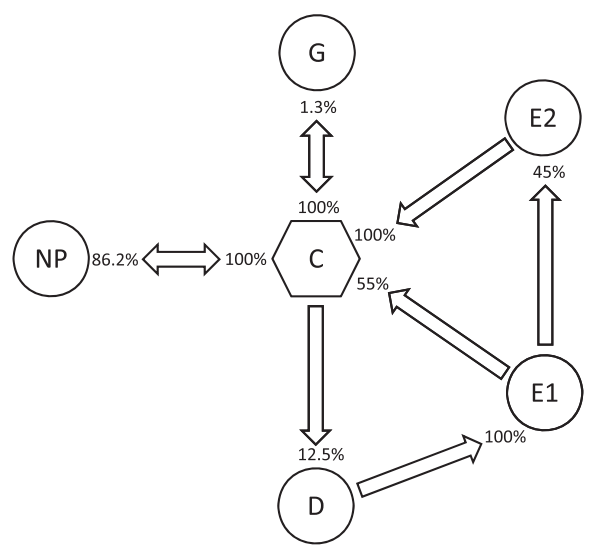

Figure 6 Typical sequence of events that are likely to occur during stylet penetration of Diaphorina citri on leaves of Citrus sinensis. The values near the arrowheads correspond to the likelihood of a certain waveform being followed by any other waveform type.

important for acquisition and inoculation of non-persistently transmitted plant viruses (Lopez-Abella et al., 1988; Powell, 1991; Martin et al., 1997).
Interestingly, pds were not observed during $\mathrm{C}$ waveforms of 20 D. citri adults on C. sinensis (160 h of EPG recordings), suggesting that intracellular stylet punctures in epidermal or parenchyma cells during stylet pathway is a very rare or absent behavior in this psyllid species. Some pd waveforms have been observed during stylet pathway of whiteflies but at a much lower rate than aphids; mealybugs produce pds more frequently than whiteflies but not as frequent as in aphids (Janssen et al., 1989; Calatayud et al., 1994; Jiang et al., 1999). Variations in amplitude and frequency of peaks in waveform $\mathrm{C}$ have been reported as well. The greenhouse whitefly, Trialeurodes vaporariorum (Westwood), starts $\mathrm{C}$ with a frequency range (10-16 Hz) similar to that of D. citri (11.5$19 \mathrm{~Hz}$ ), but a decline is observed with probing time (Janssen et al., 1989). This frequency range is lower $(5-10 \mathrm{~Hz})$ for the sweet potato whitefly, Bemisia tabaci (Gennadius), whose C waveform amplitude varied between 10 and 60\% (Jiang et al., 1999). The cassava mealybug, P. manihoti Matile-Ferrero, also showed a lower frequency $(\leq 11 \mathrm{~Hz})$ in C (Calatayud et al., 1994) compared with $D$. citri. 
We observed intact epidermal and parenchyma cells surrounding the salivary sheaths of D. citri (Figure 4C-F), suggesting that stylet pathway during waveform $\mathrm{C}$ is intercellular. In other sternorrhynchans, e.g., whiteflies and mealybugs, waveform C represents intercellular stylet pathway activity (Janssen et al., 1989; Calatayud et al., 1994; Jiang \& Walker, 2003). Nevertheless, our histological observations of salivary sheaths of $D$. citri were performed with light microscopy, which is less precise than the electron microscopy used by other studies to ascertain intercellular penetration of such small insects. Analyses of thin sections by transmission electron microscopy would be necessary to determine if the sheath is laid down strictly between cell walls or if it can cross the wall and stay outside the cell (in the space between the cell wall and the plasmalemma).

\section{Waveform G}

Because of the low rate of occurrence of waveform $\mathrm{G}$ after C $(1.3 \%)$ during the EPG recordings, we were unable to perform histological correlations to establish salivary sheath termini position in plant tissue. However, G waveform appearance shows striking similarities with the $G$ waveform described for aphids, which is correlated with sap ingestion in xylem vessels (Spiller et al., 1990). In aphids, G shows a frequency range of 4-9 Hz, extracellular voltage level, and different electrical signal origin for waves (emf) and peaks (R) (van Helden \& Tjallingii, 2000). In the present study, we observed similar characteristics in the $G$ waveform of $D$. citri, which presents less frequency variation for waves $(5-7 \mathrm{~Hz})$ and peaks $(6-8 \mathrm{~Hz})$.

Although we have not confirmed D. citri ingestion activity or stylet tip position in citrus xylem by histology or honeydew excretion analysis, the occurrence of a $G$ waveform strongly suggests that this psyllid species may occasionally ingest xylem sap, as already shown for aphids (Spiller et al., 1990). Only 25\% of D. citri adults performed waveform $\mathrm{G}$ in a few probes during a total of $160 \mathrm{~h}$ of EPG recordings; thus, it is unlikely that this psyllid uses xylem sap as a source of nutrients. In addition, xylem sap is mainly comprised of water and mineral salts (Gollan et al., 1992), with low concentration of organic compounds (Andersen et al., 1989). Nevertheless, it might be an important source of water, avoiding insect dehydration. An EPG study carried out with Aphis fabae Scopoli showed that ingestion time in xylem increased considerably when insects were submitted to a fasting period prior to plant penetration, suggesting that xylem feeding may be a strategy for maintaining aphid water balance (Spiller et al., 1990). In fact, we noted a substantial increase in the rate of occurrence of a G-like waveform when the psyllid adults were starved for $24 \mathrm{~h}$, indicating that the characterized
G-like waveform probably represents ingestion from xylem vessels and that $D$. citri uses a strategy similar to that of aphids to maintain water balance when deprived from feeding. The association of psyllid starvation with higher occurrence of $\mathrm{G}$ supports the hypothesis that xylem ingestion takes place during this waveform in D. citri, as already demonstrated for aphids (Spiller et al., 1990).

\section{Waveform D}

Waveform D was always associated with the phloem tissue based on histology and occurs between waveforms $\mathrm{C}$ and E1. Its positive voltage level indicates extracellular activity, without pds. The behavioral activity associated with waveform $\mathrm{D}$ is unknown, but $\mathrm{D}$ appears to be a reliable indicator of first contact with phloem tissue, because it always occurs prior to a pd, which presumably represents stylet penetration of sieve elements. However, this assumption cannot be proved because the various cell types in phloem tissue (i.e., sieve elements, companion cells, etc.) cannot be distinguished with light microscopy. Thus, it is not known whether D represents sieve element contact. The letter D was first used by Tjallingii (1978) to designate an aphid waveform associated with phloem sap ingestion, and equivalent to the waveform 'I' described by Mclean \& Kinsey (1964) to represent ingestion in aphids. However, there was no correlation with ingestion for waveform $\mathrm{D}$ at the time, and waveforms associated with salivation and ingestion in phloem were later named $\mathrm{E} 1$ and $\mathrm{E} 2$, respectively (Tjallingii, 1990). Thus, in the present study we decided to recover the old nomenclature $(\mathrm{D})$ to designate this additional phloem-associated waveform.

As far as we know, this is the first report of a phloemrelated waveform with an extracellular voltage level preceding E1. Aphids and mealybugs, e.g., start the phloem phase with a potential drop right after waveform $\mathrm{C}$, which represents puncture of a sieve element and subsequent salivation (waveform E1; Tjallingii, 1978, 1988; Calatayud et al., 1994; Prado \& Tjallingii, 1994). For the greenhouse whitefly, T. vaporariorum, no waveform was observed between $\mathrm{C}$ and the phloem waveform $\mathrm{E}$ (pd) (Janssen et al., 1989). When nymphs of the whitefly Bemisia argentifolii Bellows \& Perring find phloem, an abrupt transition from extracellular to intracellular voltage level is observed, originating a waveform named J (Jiang \& Walker, 2003). Waveform $\mathrm{J}$ is brief and also does not have a known biological activity. Nevertheless, unlike waveform $\mathrm{D}$ of $\mathrm{D}$. citri, it has an intracellular voltage level. Jiang \& Walker (2003) proposed that $\mathrm{J}$ could represent the beginning of the phloem phase, or yet a preparatory activity before the main activities in the phloem. This type of behavior during onset of the phloem phase was not observed for nymphs of T. vaporariorum (Lei et al., 1996). 
Waveform D seems to represent a transition behavior between pathway and phloem phases, which may be unique to psyllids, as no similar waveform has been reported for other Sternorrhyncha. However, by using the AC-EPG system, Ulman \& McLean (1988) found no waveform with similar characteristics for the pear psylla, P. pyricola.

\section{Waveforms E1 and E2}

E1 and E2 waveforms are associated with the phloem phase of $D$. citri and very likely represent salivation and ingestion in the sieve elements, respectively, as previously demonstrated for aphids (Tjallingii, 1990; Prado \& Tjallingii, 1994). Some lines of evidence support the hypothesis that E1 and E2 waveforms of D. citri are identical to those described for aphids: (1) although light microscopy does not provide sufficient resolution to conclude about precise stylet tip position in or outside cells, all histological sections showed salivary sheaths ending in the phloem tissue during E1 or E2 (one of them close to a sieve element; Figure 5C,D); (2) a negative voltage level is maintained throughout E1 and E2, indicating intracellular position of stylet tips whereas the membrane potential is maintained as well (Tjallingii, 1985); (3) similar waveform shape and frequency range, with upward peaks $(5-7.5 \mathrm{~Hz})$ for E1 and downward peaks (3-9 Hz) for E2. In aphids, waveforms E1 and E2 show frequency ranges of $2-4$ and $4-9 \mathrm{~Hz}$, respectively (van Helden \& Tjallingii, 2000).

Association of phloem sap ingestion with E2 waveform was indirectly inferred based on the analysis of acquisition of the phloem-limited bacterium, Ca. L. asiaticus by D. citri. The results showed that bacterial acquisition occurred exclusively when psyllids were able to stay on E2 for $1 \mathrm{~h}$ on infected plants, indicating that phloem sap ingestion takes place during E2. In addition, no cell type other than sieve elements in phloem provides a continually renewing source of fluid that could sustain waveform durations as long as seen with E2 (average of $2.5 \mathrm{~h}$ per event). For aphids, E2>10 min is indicative of sustained phloem sap ingestion (Tjallingii, 1994).

The probing behavior associated with the phloem phase appears to be a conserved character in Sternorrhyncha, because similar waveforms have been reported in this phase for aphids, whiteflies, mealybugs, and (now) psyllids. Calatayud et al. (1994) proposed that waveforms E1 and E2 produced by the mealybug $P$. manihoti are identical to the ones of aphids. These similarities in phloem-associated waveforms in relation to aphids were also noted in studies with whiteflies (Janssen et al., 1989; Lei et al., 1996; Jiang et al., 1999). In the case of the psyllid D. citri, further studies are needed to establish a solid correlation of E1 with salivation into sieve elements, as shown for aphids.
The fact that E1 always starts with a pd after D waveform, suggests that it is performed after stylet puncture into a living cell, possibly phloem sieve elements. Yet, detailed histological analyses of thin sections of salivary sheath termini by transmission electron microscopy would be necessary to definitively prove that psyllid stylet tips are inside sieve elements during E1.

In addition, phloem-limited bacteria, e.g., Liberibacter, could be used as markers in transmission experiments designed to establish the correlation of E1 with salivation, as performed by Prado \& Tjallingii (1994) using the circulative aphid-transmitted Barley yellow dwarf luteovirus. By using $\mathrm{Ca}$. L. asiaticus as an acquisiton marker in the present study, we already obtained evidence that phloem sap ingestion by $D$. citri adults occurs during waveform E2. Because observed acquisition efficiency by adults was low $(6 \%)$, further correlation studies involving bacterial acquisition could be carried out with $D$. citri nymphs, which are known to acquire this bacterium more efficiently than adults (Rogers et al., 2008). Excretion analysis by using honeydew 'clocks' (Lei et al., 1996) is an additional tool that could be used in the future to determine ingestion activity associated with $D$. citri waveforms. By analyzing video images taped with a digital camera during some EPG recordings, a technique successfully used for recording honeydew excretion of a sharpshooter (Miranda et al., 2009), we were unable to visualize honeydew droplets of D. citri in the present study (data not shown). We did observe the production of a thread-like secretion, as previously reported for D. citri nymphs (Tsai \& Liu, 2000); but some insects produced the thread-like substance when walking on the leaves (non-probing), suggesting that this type of secretion does not necessarily match the exact moment of ingestion.

In summary, this study provides detailed and original information about various aspects of probing behavior of D. citri on citrus. The description of DC-EPG waveforms associated with stylet activities of this important vector constitutes a fundamental step for the application of the EPG technique in future studies related to mechanisms of host plant resistance, pesticide action, and transmission of Ca. Liberibacter species. It will be particularly important to determine stylet activities and time periods required for pathogen acquisition and inoculation, as well as to establish effective control tactics for preventing disease spread in citrus groves.

\section{Acknowledgements}

The authors acknowledge Freddy Tjallingii and Elaine Backus for critical review and suggestions that greatly improved the quality of this manuscript, as well as Marli 
K. M. Soares (Universidade de São Paulo, Brazil) and Helvécio D. Coletta-Filho, for instructions on plant histology and RT-PCR detection procedures, respectively. They also thank Conselho Nacional de Desenvolvimento Cientifico e Tecnológico (CNPq, Brazil) for the scholarships awarded to the first and last authors, as well as Fundação de Amparo a Pesquisa do Estado de São Paulo (FAPESP, Brazil), and Spanish Ministry of Science and Innovation (grant AGL2007-66399-C03-02/AGR) for financial support to this research. This study was part of the doctoral thesis developed by the first author in the Graduate Program of Entomology, at ESALQ/USP.

\section{References}

Almeida RPP \& Backus EA (2004) Stylet penetration behaviors of Graphocephala atropunctata (Signoret) (Hemiptera, Cicadellidae): EPG waveform characterization and quantification. Annals of the Entomological Society of America 97: 838-851.

Alvarez AE, Tjallingii WF, Garzo E, Vleeshouwers V, Dicke M \& Vosman B (2006) Location of resistance factors in the leaves of potato and wild tuber-bearing Solanum species to the aphid Myzus persicae. Entomologia Experimentalis et Applicata 121: 145-157.

Ameline A, Couty A, Dugravot S, Campan E, Dubois F \& Giordanengo P (2007) Immediate alteration of Macrosiphum euphorbiae host plant-selection behaviour after biotic and abiotic damage inflicted to potato plants. Entomologia Experimentalis et Applicata 123: 129-137.

Andersen PC, Brodbeck BV \& Mizell RF (1989) Metabolism of amino acids and organic acids and sugars extracted from the xylem fluid of four host plants by Homalodisca coagulata. Entomologia Experimentalis et Applicata 50: 149-159.

Backus EA (1994) History, development and applications of AC electronic insect feeding monitors. History, Development and Applications of the AC Electronic Insect Feeding Monitors (ed. by MM Ellsbury, EA Backus \& DE Ullman), pp. 1-15. Entomological Society of America, Lanham, MD, USA.

Backus EA, Cline AR, Ellerseick MR \& Serrano MS (2007) Lygus hesperus (Hemiptera: Miridae) feeding on cotton: new methods and parameters for analysis of nonsequential electrical penetration graph data. Annals of the Entomological Society of America 100: 296-310.

Bové JM (2006) Hunglongbing: a destructive, newly-emerging, century-old disease of citrus. Journal of Plant Pathology 88: $7-37$.

Calatayud PA, Rahbé Y, Tjallingii WF, Tertuliano M \& Le Rü B (1994) Electrical recording feeding behavior of cassava mealybug on host and non-host plants. Entomologia experimentalis et Applicata 72: 219-232.

Capoor SP, Rao DG \& Viswanath SM (1972) Diaphorina citri Kuwayma, a vector of the greening disease of citrus in India. Indian Journal of Agricultural Sciences 37: 572-576.
Carlos EF, Coletta-Filho HD, Targon MLN \& Machado MA (2006) Quantitative real time PCR base on TAQMAN probes to molecular detection of Candidatus Liberibacter asiaticus and Ca. L. americanus. Huanglongbing-Greening International Workshop (ed. by AJ Ayres, E Nogueira, JRP Parra, JM Bové, MA Machado \& O Bergamashi), p. 81. Fundectrus, Ribeirão Preto, São Paulo, Brazil, July 16-20.

Chatterjee S, Almeida RPP \& Lindow S (2008) Living in two worlds: the plant and insect lifestyles of Xylella fastidiosa. Annual Review of Phytopathology 46: 243-271.

Coletta-Filho HD, Targon MLPN, Takita MA, De Negri JD, Pompeu J Jr \& Machado MA (2004) First report of the causal agent of huanglongbing ('Candidatus Liberibacter asiaticus') in Brazil. Plant Disease 88: 1382.

Coletta-Filho HD, Carlos EF, Alves KCS, Pereira MAR, Boscariol-Camargo RL et al. (2009) In plant multiplication and graft transmission of 'Candidatus Liberibacter asiaticus' revealed by real-time PCR. European Journal of Plant Pathology doi: 10.1007/510658-009-9523-2.

Collar JL \& Fereres A (1998) Nonpersistent virus transmission efficiency is determined by aphid probing behavior during intracellular punctures. Environmental Entomology 27: 583591.

Deng X, Li J, Xu J, Fang S, Li H \& Chen J (2006) A method for a quick detection of huanglongbing agent from asiatic citrus psyllid (Diaphorina citri Kuwayama). Huanglongbing-Greening International Workshop (ed. by AJ Ayres, E Nogueira, JRP Parra, JM Bové, MA Machado \& O Bergamashi), p. 85. Fundectrus, Ribeirão Preto, São Paulo, Brazil, July 16-20.

Fereres A \& Collar JL (2001) Analysis of noncirculative transmission by electrical penetration graphs. Virus-Insect-Plant Interactions (ed. by KF Harris, OP Smith \& JE Duffus), pp. 87-109. Academic Press, London, UK.

Garzo E, Soria C, Gomez-Guillamon ML \& Fereres A (2002) Feeding behavior of Aphis gossypii resistant accessions of different melon genotypes (Cucumis melo). Phytoparasitica 30: 129-140.

Gollan T, Shulze ED \& Schurr U (1992) Stomatal response to drying soil in relation to changes in the xylem sap composition of Helianthus annuus. II. Stomatal sensitivity to abscisic acid imported from the xylem sap. Plant Cell and Environment 15: 561-567.

Gottwald TR, da Graça JV \& Bassanezi RB (2007) Citrus Huanglongbing: the pathogen and its impact. Plant Health Progress doi:10.1094/PHP-2007-0906-01-RV.

Gray SM \& Banerjee N (1999) Mechanisms of arthropod transmission of plant and animal viruses. Microbiology and Molecular Biology Reviews 63: 128-142.

Halbert SE (2005) The discovery of huanglongbing in Florida. Second International Citrus Canker and Huanglongbing Research Workshop (ed. by TR Gottwald, WN Dixon, JH Graham \& P Berger), p. 50. Florida Department of Agriculture \& Consumer Services, Orlando, Florida, USA, November 7-11.

van Helden M \& Tjallingii WF (2000) Experimental design and analysis in EPG experiments with emphasis on plant resistance research. Principles and Applications of Electronic Monitoring and Other Techniques in the Study of Homopteran Feeding 
Behavior (ed. by GP Walker \& EA Backus), pp. 144-171. Entomological Society of America, Lanham, MD, USA.

Hodkinson ID (1974) The biology of the Psylloidea (Homoptera): a review. Bulletin of Entomological Research 64:325-339.

Hogenhout SA, Ammar ED, Whitfield AE \& Redinbaugh MG (2008) Insect vector interactions with persistently transmitted viruses. Annual Review of Phytopathology 46: 327-359.

Janssen JAM, Tjallingii WF \& van Lenteren JC (1989) Electrical recording and ultrastructure of stylet penetration by the greenhouse whitefly. Entomologia Experimentalis et Applicata 52: 69-81.

Jiang YX \& Walker GP (2003) Electrical penetration graphs of the nymphal stage of Bemisia argentifolii. Entomologia Experimentalis et Applicata 109: 101-111.

Jiang YX, Lei H, Collar JL, Martin B, Muñiz M \& Fereres A (1999) Probing and feeding behavior of two distinct biotypes of Bemisia tabaci (Homoptera: Aleyrodidae) on tomato plants. Journal of Economic Entomology 92: 357-366.

Karnovsky MJ (1965) A formaldehyde-glutaraldehyde fixative of high osmolarity for use in electron microscopy. Journal of Cell Biology 27: 137-138.

Lei H, Tjallingii WF, van Lenteren JC \& Xu RM (1996) Stylet penetration by larvae of the greenhouse whitefly on cucumber. Entomologia Experimentalis et Applicata 79: 77-84.

Lopez-Abella D, Bradley RHE \& Harris KF (1988) Correlation between stylet paths made during superficial probing and the ability of aphids to transmit nonpersistent viruses. Advances in Disease Vector Research 5: 251-285.

Martin B, Collar JL, Tjallingii WF \& Fereres A (1997) Intracellular salivation and ingestion by aphids may cause inoculation and acquisition of nonpersistently transmitted plant viruses. Journal of General Virology 78: 2701-2705.

Mclean DL \& Kinsey MG (1964) A technique for electronically recording aphid feeding and salivation. Nature 202: 1358-1359.

Miranda MP, Fereres A, Da Appezzato G \& Lopes JRS (2009) Characterization of electrical penetration graphs of Bucephalogonia xanthophis, a vector of Xylella fastidiosa in citrus. Entomologia Experimentalis et Applicata 130: 35-46.

Moreno A, Palacios I, Blanc S \& Fereres A (2005) Intracellular salivation is the mechanism involved in the inoculation of Cauliflower mosaic virus by its major vectors, Brevicoryne brassicae and Myzus persicae. Annals of the Entomological Society of America 98: 763-769.

Murray M \& Thompson WF (1980) Rapid isolation of highmolecular-weight plant DNA. Nucleic Acids Research 8: 43214325 .

Nault LR (1997) Arthropod transmission of plant viruses: a new synthesis. Annals of the Entomological Society of America 90: 521-541.

Powell G (1991) Cell membrane punctures during epidermal penetrations by aphids: consequences for the transmission of two potyviruses. Annals of Applied Biology 119: 313-321.

Powell G, Tosh CR \& Hardie J (2006) Host plant selection by aphids: behavioral, evolutionary, and applied perspectives. Annual Review of Entomology 51: 309-330.
Prado E \& Tjallingii WF (1994) Aphid activities during sieve element punctures. Entomologia Experimentalis et Applicata 72: 157-165.

Reese JC, Margolies DC, Backus EA, Noyes S, Bramelcox P \& Dixon AGO (1994) Characterization of aphid host plant resistance and feeding behavior through use of a computerized insect feeding monitor. History, Development and Applications of the AC Electronic Insect Feeding Monitors (ed. by MM Ellsbury, EA Backus \& DE Ullman), pp. 70-101. Entomological Society of America, Lanham, MD, USA.

Rogers ME, Brlansky RH, Ebert TA, Serikawa RH, Schumann RA \& Stelinski KP (2008) Acquisition of Candidatus Liberibacter asiaticus by the Asian citrus psyllid, Diaphorina citri, and the potential use of insecticides to prevent pathogen transmission. International Research Conference on Huanglongbing (ed. by TR Gottwald \& JH Graham), p. 207. Florida Department of Agriculture \& Consumer Services, Orlando, Florida, USA, December 1-5.

Sakai WS (1973) Simple method for differential staining of paraffin embedded plant material using toluidine blue. Stain Technology 48: 247-249.

Sarria E, Cid M, Garzo E \& Fereres A (2009) Workbook for automatic parameter calculation of EPG data. Computers and Electronics in Agriculture 67: 35-42.

Sechler A, Schuenzel EL, Cooke P, Donnua S, Thaveechai N et al. (2009) Cultivation of 'Candidatus Liberibacter asiaticus', 'Ca. L. africanus', and ' $\mathrm{Ca}$. L. americanus' associated with Huanglongbing. Phytopathology 99: 480-486.

Spiller NJ, Koenders L \& Tjallingii WF (1990) Xylem ingestion by aphis a strategy for maintaining water balance. Entomologia Experimentalis et Applicata 55: 101-104.

Stafford CA, Walker GP \& Creamer R (2009) Stylet penetration behavior resulting in inoculation of beet severe curly top virus by beet leafhopper, Circulifer tenellus. Entomologia Experimentalis et Applicata 130: 130-137.

Teixeira DDC, Saillard C, Eveillard S, Danet JL, Da Costa PI et al. (2005) 'Candidatus Liberibacter americanus' associated with citrus huanglongbing (greening disease) São Paulo State, Brazil. International Journal of Systematic and Evolutionary Microbiology 55: 1857-1862.

Tjallingii WF (1978) Electronic recording of penetration behavior by aphids. Entomologia Experimentalis et Applicata 24: 721-730.

Tjallingii WF (1985) Electrical nature of recorded signals during stylet penetration by aphids. Entomologia Experimentalis et Applicata 38: 177-186.

Tjallingii WF (1988) Electrical recording of stylet penetration activities. Aphids, their Biology, Natural Enemies and Control, Vol.2B (ed. by AK Minks \& P Harrewijn), pp. 95-108. Elsevier, Amsterdam, The Netherlands.

Tjallingii WF (1990) Continuous recording of stylet penetration activities by aphids. Aphids-Plant Genotype Interactions (ed. by RK Campbell \& RD Eikenbary), pp. 89-99. Elsevier, Amsterdam, The Netherlands.

Tjallingii WF (1994) Sieve element acceptance by aphids. European Journal of Entomology 91: 47-52. 
Tsai JH \& Liu YH (2000) Biology of Diaphorina citri (Homoptera: Psyllidae) on four host plants. Journal of Economic Entomology 93: 1721-1725.

Tsai JH, Wang JJ \& Liu YH (2002) Seasonal abundance of the asian citrus psyllid, Diaphorina citri (Homoptera: Psyllidae) in southern Florida. Florida Entomologist 85: 446-451.

Ullman DE \& McLean DL (1988) The probing behavior of the summer-form pear psylla. Entomologia Experimentalis et Applicata 47: 115-125.

Walker GP (2000) A beginner's guide to electronic monitoring of Homopteran probing behavior. Principles and Applications of Electronic Monitoring and Other Techniques in the Study of Homopteran Feeding Behavior (ed. by GP Walker \& EA Backus), pp. 14-40. Entomological Society of America, Lanham, MD, USA.
Wayadande AC \& Nault LR (1996) Leafhoppers on leaves: an analysis of feeding behavior using conditional probabilities. Journal of Insect Behavior 9: 3-22.

Wensler RJD \& Filshie BK (1969) Gustatory sense organs in the food canal of aphids. Journal of Morphology 129: 473-492.

Yamamoto PT, Felippe MR, Garbim LF, Coelho JHC, Ximenes NL et al. (2006) Diaphorina citri Kuwayama (Hemiptera: Psyllidae): vector of the bacterium Candidatus Liberibacter americanus. Huanglongbing-Greening International Workshop (ed. by AJ Ayres, E Nogueira, JRP Parra, JM Bové, MA Machado \& O Bergamashi), p. 96. Fundectrus, Ribeirão Preto, São Paulo, Brazil, July 16-20. 